\title{
Product reliability and warranty period as a cost-forming factors
}

\author{
Nataly Podolyakina ${ }^{1}$ \\ 1 Department of Economics, Financial and Management, Faculty of Management and Economics, Transport and Telecommunication Institute, \\ Lomonosova 1, LV 1019 Riga, Latvia
}

Corresponding author: Nataly Podolyakina (npod@tsi.Iv)

Received 14 November 2015

Accepted 30 April 2016

Published 30 November 2016

Academic editor:

Živile Tunčikiené

\section{Keywords}

cost structure warranty servicing warranty period reliability level probability of failure of the product unit cost

\section{JEL Classification}

\begin{abstract}
The relevance of this study is determined by the fact that, in modern conditions, the manufacturers of high-tech products offer long-term warranty service for their products aiming at receiving the consumer. In turn, the frequency of warranty service depends on the probability of trouble-free operation of the product in a certain time interval. However, increasing the uptime of the products and increase the warranty period results in increased costs. Therefore, the purpose of this study is to develop a model that allows determining the impact of the following factors on the product cost: the reliability of the manufactured products and the term of their warranty. To achieve the goal of the research there has been determined the content of warranty service, has been introduced the integrated indicator of quality warranty services, and has been shown the level of products reliability as a dependence from the costs of their manufacturing and warranty service. The novelty of this study is estimation of the manufacturer's cost depending on the way of providing the warranty service, either by repair, or by complete replacement of the failed product. The research results provide competitive advantages to manufacturers of high-tech products since it enables to find the efficient period and intensity of the warranty service.
\end{abstract}

\section{Introduction}

Every company is fighting for the consumer under the circumstances of modern market economy. To attract and retain consumers of their products, companies develop and offer a huge range of additional features that make the produced product more attractive. These features include favorable terms and conditions of payment, flexible system of discounts for customers, as well as a system of products warranty.

The consequence of technical progress is the production of increasingly high-tech devices and mechanisms there are various requirements towards the level of their reliability.

Consumers need assurance that the product will perform satisfactorily over the useful life of the product. There are many different aspects to warranty and these have been studied by researchers from many different disciplines.

The higher the reliability requirements towards the product are, the higher the quality of warranty service is. In their turn, these aspects affect the manufacturer's costs.
The warranty servicing costs vary from $2-10 \%$ of the sale price depending on the product and the manufacturer. As a result, warranty and product reliability are very important in the context of new product development (Deniaud et al. 2016).

Reliability of a product conveys the concept of dependability, successful operation or performance and the absence of failures. It is an external property of great interest to both manufacturer and consumer. Unreliability (or lack of reliability) conveys the opposite. A more technical definition is the following:

- The reliability of a product (system) is the probability that the product (system) will perform its intended function for a specified time period when operating under normal (or stated) environmental conditions (Blischke and Murthy 2000).

- The reliability of a product gets determined by the decisions made during the pre-production stages (Front-end, Design, Development) and the pro- 
duction stage of the product life cycle (Murthy and Djamaludin 2002).

Both warranty and reliability have received a lot of attention over the last fifty years (Murthi 2008).

The area of warranty has been studied by researchers from many different areas such as economic, engineering, statistics and more. A number of techniques have been used as a method in solving warranty problem. In past few years, there has been an increased used of statistical methods instead of soft computing methods in warranty related applications. However, soft computing methods have been used by many researchers in the other research area which can provide some feasible solutions for the complex real-world problems (Majid et al. 2013).

Thus, the relevance of the present study is obvious; the research is aimed at assessing the impact of reliability of manufactured products on the cost structure of the manufacturer providing the warranty repair of the product. To achieve this goal there have been identified a number of objectives:

- To determine the essence of the warranty repair and service.

- To specify the types of warranty service.

- To determine the order of formation of the manufacturer's costs of the warranty service of products produced at a specified level of reliability.

- To analyse the relationship between the manufacturer's cost and a warranty period of service and reliability of manufactured products.

Reliability theory deals with the interdisciplinary use of probability, statistics and stochastic modelling, combined with engineering insights into the design and the scientific understanding of the failure mechanisms, to study the various aspects of reliability. As such, it encompasses the following: reliability modelling, reliability analysis, reliability engineering, reliability science, reliability management.

Reliability Improvement Warranty policies are offered with complex systems intended for long use. The basic idea is to extend the notion of a basic consumer warranty to include guarantees on the reliability of the item and not just on its immediate or short-term performance (Murthy et al. 2007).

The novelty of this article lies in the fact that it allows the manufacturer, using mathematical calculations, make an economically sound choice between repair and replacement of the failed product during the warranty period. It is obvious that the probability of failure-free operation of the product will decrease with the increase of its useful life. The originality of this article is determined by using methods of mathematical statistics and probability theory in the dependence evaluation according to the manufacturer's costs to the duration of the warranty period and reliability of manufactured products.
Due to the fact that the reliability of the product is a probabilistic value, which is determined in dependence on the operational period of the product, the methodology of this study is based on the methods of probability theory. The use of these methods makes it possible to obtain a more or less reliable information on the probability of failure-free operation of the product during the warranty period and allowed to make a cost-dependent mathematical model of the manufacturer, that provides warranty service with a given probability of failure-free operations.

\section{Essence of the warranty repair and service}

It is impossible to hope for success in the modern conditions if the enterprise-manufacturer does not service their products after manufacturing (Akyildiz and Wang 2005).

Product warranty is a set of works, performed by manufacturers with the aim of providing technical and economic satisfaction and legal protection of the customer, as a result of purchased products use.

Warranty is an important element of marketing new products, as better warranty signals higher product quality and provides greater assurance to customer. In the purchase decision of a product, buyers typically compare characteristics of comparable model of competing brands (Jeyakumar and Paul Robert 2010).

The principle of modern warranty service is that the manufacturer takes responsibility for maintaining product functionality during the whole period of its operation (Wang and Su 2016). The high competitiveness of the product is largely determined by high-quality warranty service, and therefore the manufacturing enterprises should not consider it as something burdensome; on the contrary, they should be oriented on good provision of this service. Well organized warranty services can not only affect the business reputation of the manufacturer, but also become an important source of income.

Therefore, the useful lifetime can be defined as the lifetime of the product in the market and can be assumed to be terminated in some finite, random time horizon. Outdated technology is not covered by lifetime warranty. Therefore, the life term can be defined in any of the following ways (Chattopadhyay and Rahman 2008):

- Technical life/Physical life - the period over which the product might be expected to last physically (up to the period when replacement or major rehabilitation is physically required).

- Technological life - the period until technological obsolescence dictating replacement due to the development of a technologically superior alternative.

- Commercial life/Economic life - the period over which the need for the product exists, the period until economic obsolescence dictates replacement with an economic alternative. 
- $\quad$ Ownership life/Social and legal life - the period until customer desire or legal ownership is retained or replacement change of ownership occurs.

There are several types of warranty services (Bolotin 1990):

- Pre-delivery service is aimed at meeting consumer demand; the manufacturer studies in details the requirements of the potential buyers to the product. The department personnel providing the warranty services are involved in the design work, in testing and evaluation, and in the documentation preparation. When the product is at the place of operation, the employees of the company-manufacturer have possibility to solve the problems appeared in the process of transportation, to install the equipment, to put it into a working state.

- After-sales service includes an aggregate of services necessary for the effective functioning of the manufactured products in the existing conditions throughout its lifecycle. After-sales warranty service is performed both before and after the sale of the product and includes the following main activities:

- determining requirements for after-sales service of consumers of manufactured product at the stage of product development (together with the main consumers);

- determining the procedure of after-sales services provision to the consumer in the process of discussing the agreement on the product supply;

- personnel training in the technical maintenance and products repair;

- $\quad$ preparation of the necessary documentation;

- preparation of the necessary infrastructure to provide after-sales service;

- development of the system of replacing the old model with the new one, working out the procedure of utilization of the old model;

- determining the range of services available to the consumer after buying the product.

After-sales service is divided into warranty and post-warranty on purely formal ground: if the works/operations, provided by the warranty are supplied free or for charge. This ground is rather formal because the cost of the work, spare parts and materials used during the warranty period, are included into selling price or in price of other (post-warranty) services.

During the warranty period the manufacturer tries to take over all the work, creating the basis for the long-term trouble-free operation of the machine, equipment, block or a part of the mechanism (Murthy et al. 2003).

In the post-warranty period the manufacturer provides the scheduled preventive works, implements repairs, supplies the customer with the spare parts, consults on the most efficient operation. All these works are carried out on the basis of the signed agreement, the implementation of which is beneficial for both parties since it reduces the standing idle of the equipment, increases the period before overhaul, reduces the number of defects, increases the safety of the equipment operation. All these features stimulate the growth of the manufacturer's position and the prestige, and allow demonstrating in the advertisement the real-life examples of high-quality work; the seller enjoys the obvious benefits: the warranty service undoubtedly strengthens the producer's position as a reliable supplier towards the consumers of the products.

No matter how perfect an innovative product is, it will surely require certain repair and services during the exploitation period (Ang et al. 2005).

Thus, warranty services and repairs is one of the most important resource-efficient activities provided by structure of modern designed innovative products. In all cases, the manufacturer bears full responsibility for the process and the results of warranty services; value and quality of these services have the greatest importance for the consumers.

Higher reliability is expected to reduce the cost of warranty returns, but at the same time to drive up the cost of product development. Thus an optimal solution is possible by finding a target reliability corresponding to the lowest value of the total expected life cycle cost (Kleyner et al. 2004).

\section{Cost formation for product warranty service and repair}

The base warranty is integral to the sale and as such factored into the sale price and the customer does not pay anything extra. Extended warranties are optional which customers purchase by paying an extra amount. These are offered by several parties - manufacturers, retailers and independent agencies such as insurance companies etc.

Providing warranty coverage doesn't come free for the manufacturer. Offering warranty always implies additional cost associated with warranty service, typically ranging between 1 and 2 percent of product sales for manufacturing companies (Kurvinen et al. 2016).

There are several different notions of warranty costs. These include warranty cost per unit, warranty cost over some interval (for example, product life cycle) and warranty costs per unit time (warranty cost rate) (Chen et al. 2015). As mentioned earlier, the warranty costs depend on product reliability and the product usage.

For products with longer lifetimes, the total warranty cost is uncertain over longer period of time due to the uncertainties of lifetime and the costs of servicing claims. If the lifetime is more than one year, the future cost will be affected by increased labour cost, inflation and devaluation of money over time (Rahman and Chattopadhyay 2015).

The warranty cost as a fraction of the sale price can vary from $1-10 \%$ depending on the product and the manufacturer. The total warranty costs for General Motors and 
Ford were over 4 billion dollars each for 2006. Through proper servicing logistics, these costs can be reduced. Murthy et al. deals with warranty logistics (Murthy et al. 2004). One particular issue is the choice between repair versus replace for a failed item under warranty. Murthy and Jack deal with this topic (Murthy and Jack 2007).

So, as it has been mentioned above, the warranty service system can comprise either complete replacement of the failed product or its repair.

However, the most important issue for the manufacturer offering the product warranty is increasing costs of the warranty implementation, to the forefront come issues related to, as well as the determination of the warranty period at which the maintenance costs are economically viable.

The only alternative to the failed product items complete substitution in the connection with the considered case is a repair (restoration). In this case the total costs of manufacturing and maintenance are:

$$
C_{\Sigma}=C_{\text {man }}+C_{r e p}
$$

where: $C_{\text {man }}, C_{\text {rep }}$ are the costs of manufacturing and repairing the failed product items accordingly.

In its turn,

$$
C_{r e p}=C_{w}+C_{s p}
$$

where: $C_{w}$ is the cost of labor (the wages of equipment troubleshooters); $C_{s p}$ is the cost of the spare parts used for repairing.

As a result:

$$
C_{\Sigma}=C_{\text {man }}+C_{w}+C_{s p}
$$

The last model is consciously restricted by the components $C_{\text {man }}, C_{w}, C_{s p}$, because such non-presented additional components as cost of the premises rented for repairing shops, the cost of the equipment depreciation etc. change only the quantitative side of the solution components but do not influence its principal issues.

If the batch of the product items is produced in $N_{1}$ amount, then:

$$
C_{\text {man }}=N_{1} C_{1}
$$

where: $C_{1}$ is the cost of manufacturing 1 item.

At warranty period $t_{g}$ one worker - employee of the enterprise-manufacturer repairs $12 n t_{g}$ items, where is the number of items repaired by one worker per month.

Thus, the total amount of the repaired product items with the probability of the non-failure operation $P=P\left(t_{g}\right)$ is equal to $(1-p) N_{1}$ (Kapur and Lamberson 1980). As a result, the number of workers needed for warranty service provision for $(1-p) N_{1}$ items during the entire warranty period $t_{g}$ is:

$$
\frac{(1-p) N_{1}}{12 n t_{g}}=\frac{\left(1-e^{-\lambda t}\right) N_{1}}{12 n t_{g}}
$$

If the wage of one worker is $C_{w 1}$ Euros per month, then the total expenses on wages of all the repairing workers during the warranty service period $t_{g}$ is equal to:

$$
C_{w}=\frac{(1-p) N_{1}}{12 n t_{g}} C_{w 1}
$$

At last, if the cost of spare parts for 1 item is $C_{s p 1}$, then the total cost of the spare parts used for repairing is equal to:

$$
C_{s p}=C_{s p 1}(1-p) N_{1}
$$

The joint solution for the Eqs (6) and (7) results in the expression for determining the total cost of manufacturing and warranty repairing of the product items with the account of the probability of the product non-failure operation (Ventsel 1969):

$$
C_{\Sigma}=N_{1} C_{1}+\frac{(1-p) N_{1}}{12 n t_{g}} C_{w 1}+C_{s p 1}(1-p) N_{1}
$$

Accomplishing the warranty repair of failed product the enterprise-manufacturer does not produce the additional items, but makes the spare parts for repairing the failed items.

Thus, the first component in the Eq. (8) does not include the co-multiplier $(2-p)$, as it happens when the failed item is substituted by the new one.

The Eq. (8) is presented as follows:

$$
C_{\sum_{r e p}}=N_{1} C_{1}+\frac{(1-p) N_{1}}{12 n t_{g}} C_{w 1}+K_{0} C_{1} N_{1}(1-p) \text {, }
$$

where: $K_{0}$ is magnification value products.

As $N_{1} C_{1}=C$, then

$$
\left(\frac{C_{\sum}}{C}\right)_{\text {rep }}=1+\frac{(1-p)}{12 n t_{g} C_{1}} C_{w 1}+K_{0}(1-p)\left(\frac{C_{w 1}}{12 n t_{g} C_{1}}+K_{0}\right)
$$

Then the notation $A=C_{w 1} / n C_{1}$ is introduced. As $p=$ $\exp \left(-\lambda t_{g}\right)$, then the Eq. (10) is (Druzhinin 1989):

$$
\left(\frac{C}{C}\right)_{\text {rep }}=1+\left(\frac{A}{12 t_{g}}+K_{0}\right)\left(1-e^{-\lambda t}\right) .
$$

First the task solution is restricted by the case of high level of the product reliability (Angrisani et al. 2006):

$$
e^{-\lambda t} \cong 1-\lambda t_{g}
$$

This correlation is valid starting with the value of non-failure not lower than $P=\exp \left(\lambda t_{g}\right) \geq 0.9$, in other words at $\lambda t_{g} \leq 0.1$.

The component $A / 12 t_{g}$ in the majority of cases is considerably lower that $K_{0}$, in other words $A / 12 t_{g}<<K_{0}$. Under this condition the expression is transformed into the ordinary ratio

$$
\left(\frac{C_{\Sigma}}{C}\right)_{\text {rep }} \cong 1+L K_{0} \lambda t_{g}
$$


If the wage of the repairing worker exceeds considerably the cost of the product items repaired per month, then the $A$ is either commensurable with the value $K_{0}$ or exceeds it.

In this case $A / 12 t_{g}$ cannot be neglected.

\section{Interconnection of the manufacturer's costs with the duration of the warranty service period and reliability of product}

Manufacturers offer many types of warranties to promote their products. Thus, warranties have become an important promotional tool for manufacturers. Warranties also generally limit the manufacturer's liability for out-of-warranty product failure. Although warranties are used by manufacturers as a competitive strategy to boost their market share, profitability and image, they are by no means cheap.

Warranties cost manufacturers a substantial amount of money. From a manufacturer's perspective, the cost of a warranty program must be estimated precisely and its effect on the firm's profitability must be studied (Saleh and Marais 2006).

Chien et al. (2004) estimated the warranty costs during the life cycle of a product in order to create a fund for warranty reserves. They considered a failure-free non-renewing warranty policy for products with age-dependent minimal repair costs, derived the s-expected warranty costs and warranty reserves, and demonstrated the feasibility of using cost information to determine warranty length (Chien et al. 2004)

They investigated preventative maintenance warranty policies for repairable products. When the length of a warranty period was pre-specified, the optimal number of preventive maintenance actions, corresponding maintenance degrees, and the maintenance schedule were jointly determined (Mustofa et al. 2015).

The expression $\left(C_{\Sigma} / C\right)_{\text {rep }} \cong 1+L K_{0} \lambda t_{g}$ shows the dependence of total aggregate costs $\left(C_{\Sigma} / C\right)_{\text {rep }}^{g}$ on the main indices $K_{0}, \lambda$ and $t_{g}$ :

- the higher $K_{0}$ is the share of the spare parts cost in relation to the product cost the higher is the intensity of the product failures $\lambda$ and warranty period $t_{g}$, the bigger are the total aggregate costs of the enterprise-manufacturer.

Generally, the dependence of the value $\left(C_{\Sigma} / C\right)_{\text {rep }}$ on the duration of the warranty service period $t_{g}$ is nonlinear; it is presented in Figure 1 basing on Table 1 data, obtained for $A=0.5, K_{0}=0.2$ and $\lambda=10^{-5} 1 / h$.

Table 1. The dependence of the value $\left(C_{\Sigma} / C\right)_{\text {rep }}$ on the duration of the warranty service period $t_{g}$.

\begin{tabular}{l|l|l|l|l|l}
\hline$t_{g}$ & 2 & 3 & 4 & 5 & 10 \\
\hline$\left(C_{\Sigma} / C\right)_{\text {rep }}$ & 1.035 & 1.049 & 1.063 & 1.075 & 1.1956 \\
\hline
\end{tabular}

According to the expression Eq. (11), at $K_{0}=0.2 t_{g} \rightarrow \infty$ $\left(C_{\Sigma} / C\right)_{\text {rep }}=1.2=0.2$. Generally

$$
\left(C_{\Sigma} / C\right)_{\text {rep }}=1+K_{0}
$$

According to the data of Table 1 , at $t_{g}=10$ years $\left(C_{\Sigma} / C\right)_{\text {rep }}=1.2$.

The ratio $\left(C_{\Sigma} / C\right)_{\text {rep }}=1+K_{0}$ shows, in particular, that in case of big warranty period $t_{g}$ the share of the spare parts cost compared to the cost of repaired product is the value determining the ratio $\left(C_{\Sigma} / C\right)_{r e p}$, characterizing total aggregate costs of the enterprise-manufacturer spent on the production and the warranty repair of the consumer's failed products.

If the probability of the non-failure operation is increased from $P$ level to $P_{1}$ level, then the product cost increases from value $C_{1}$ to value $C_{1}{ }^{\prime}$; the cost of spare parts for 1 product item increases from value $C_{s p 1}$ to value $C_{s p 1}^{\prime \prime}$; then the total cost of manufacturing and repairing with the account of the probability of the product non-failure operation is determined as follows:

$$
C_{\Sigma}^{\prime \prime}=N_{1} C_{1}^{\prime \prime}+\frac{(1-p) N_{1}}{12 n t_{g}} C_{w 1}+C_{s p 1}^{\prime \prime}(1-p) N_{1}
$$

The cost of spare parts needed for 1 product item is the part of the product cost, that is $C^{\prime \prime}{ }_{s p 1}=K_{0} C^{\prime \prime}{ }_{1}$, where $K_{0}<$ 1 and it is assumed that $K_{0}-$ const. Taking into account this condition:

$$
\begin{aligned}
& C_{\Sigma}^{\prime \prime}=N_{1} C_{1}^{\prime \prime}+\frac{(1-p) N_{1}}{12 n t_{g}} C_{w 1}+K_{0}\left(1-p_{1}\right) N_{1} C_{1}^{\prime \prime}= \\
& =N_{1} C_{1}^{\prime \prime}\left[\frac{1-p_{1}}{12 n t_{g} C_{1}^{\prime \prime}} C_{w 1}+K_{0}\left(1-p_{1}\right)\right]
\end{aligned}
$$

The last expression for $C^{\prime \prime}$ considering the above-mentioned ratio is as follows:

$$
\frac{C_{\sum}^{\prime \prime}}{C}=\left[1+K^{1}\left(\frac{a}{k}\right)\right]\left[1+\frac{(1-p) A}{12 n t_{g} C_{1}\left[1+K^{1}\left(\frac{a}{k}\right)\right]}\right] C_{w 1}+K_{0}\left(1-p_{1}\right),
$$

where $C=N_{1} C_{1}$.

$$
A=C_{w 1} / n C_{1}
$$

and $n C_{1}$ is the cost of $n$ product items restored by one repairing worker per month. As a result

$$
\frac{C_{\sum}^{\prime \prime}}{C}=\left[1+K^{1}\left(\frac{a}{k}\right)\right]\left[1+\frac{(1-p) A}{12 n t_{g} C_{1}\left[1+K^{1}\left(\frac{a}{k}\right)\right]}\right]+K_{0}\left(1-p_{1}\right) .
$$

Thus, the value of the ratio of $C^{\prime \prime}{ }_{\Sigma} / C$ is the function of a number of parameters:

$$
\frac{C_{\Sigma}^{\prime \prime}}{C}=f\left(p_{1}, \frac{a}{K}, A, K_{0}\right) \text {. }
$$


In this case, values $a / k, A, K_{0}$ can change significantly. The value $K^{1}=\ln p / \ln p_{1}$ is unambiguously determined by the value of probability of the product non-failure operation and by the initial value of the probability of non-failure operation.

Table 1 demonstrates the values of the relative $\operatorname{cost} C_{\Sigma}^{\prime \prime} / C$ for the warranty service period that is equal to 2 years for the product item at and the basic value of the probability of the non-failure operation $A=0.5$, on the basis of which the growth of the product reliability is estimated.

Herewith the value of the growth of the cost of non-failure operation $a / K$ changes within the limits of 0.02 to 0.2 for each value of $K_{0}=0.2 ; 0.4 ; 0.6$.

Figures 2, 3 and 4 shows the nature of dependence the relative cost on the growth of reliability for various values of the values $K_{0}$ and $a / K$.

The data from the Table 2 and the Figures 2, 3 and 4 demonstrate that the dependence of the change of the share of the spare parts cost on the product cost affects significantly the cost of manufacturing and repairing the failed product items. In this case it is quite evident that the growth of the cost $a / K$ of increasing the product reliability the total costs increase.

Moreover, the data from Table 2 and the shape of the curves on the figure prove that the growth of the costs of the product reliability increase for every fixed value $K_{0}=$ $0.2 ; 0.4 ; 0.6$ results in situation when the optimal value of the probability of the non-failure operation, providing the conditions of the minimal costs, shifts to the area of the reduced values of the probability of product non-failure operation; it is common with the case of substitution of the failed product items by new ones.

Concerning the value $K_{0}$, its growth shifts the value of the optimal probability of non-failure operation to the area of higher values. Nevertheless, the value of the total costs of the enterprise-manufacturer of producing and repairing the failed product increase simultaneously with $K_{0}$ growth.

There considered the dependence of the impact of the warranty period $t_{g}$ and the value $A$ of one worker's wage

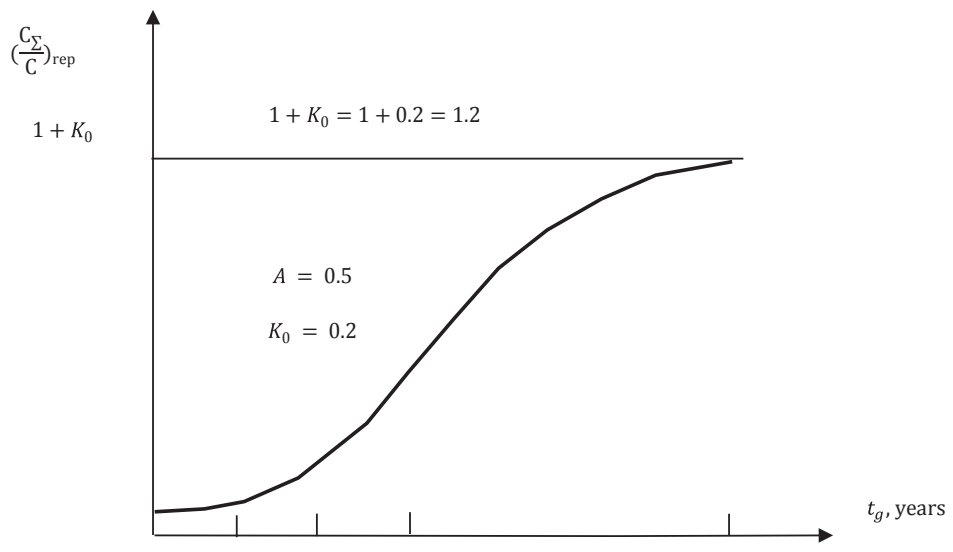

Figure 1. The dependence of the total cost of the enterprise on the duration of the warranty service period for the repair of failed product items.

Table 2. The nature of dependence the relative cost on the growth of reliability for various values of the values $K_{0}$ and $a / K$.

\begin{tabular}{|c|c|c|c|c|c|}
\hline \multicolumn{6}{|c|}{ Meanings $C \Sigma \Sigma / C$ at $t_{\mathrm{g}}=$ years; $A=0.5 ; P=0.5$} \\
\hline \multirow{2}{*}{$K_{0}$} & \multirow{2}{*}{$a / K$} & \multicolumn{4}{|c|}{$P_{1}$} \\
\hline & & 0.6 & 0.7 & 0.8 & 0.9 \\
\hline \multirow{4}{*}{0.2} & 0.02 & 1.120 & 1.107 & 1.160 & - \\
\hline & 0.05 & 1.162 & 1.169 & - & - \\
\hline & 0.10 & 1.24 & 1.27 & - & - \\
\hline & 0.20 & 1.38 & 1.48 & - & - \\
\hline \multirow{4}{*}{0.4} & 0.02 & 1.20 & 1.17 & 1.15 & 1.18 \\
\hline & 0.05 & 1.247 & 1.235 & 1.252 & 1.384 \\
\hline & 0.10 & 1.326 & 1.344 & - & - \\
\hline & 0.20 & 1.48 & 1.56 & - & - \\
\hline \multirow{4}{*}{0.6} & 0.02 & 1.28 & 1.232 & 1.194 & 1.202 \\
\hline & 0.05 & 1.333 & 1.301 & 1.298 & 1.411 \\
\hline & 0.10 & 1.417 & 1.415 & 1.472 & - \\
\hline & 0.20 & 1.585 & 1.644 & - & - \\
\hline
\end{tabular}




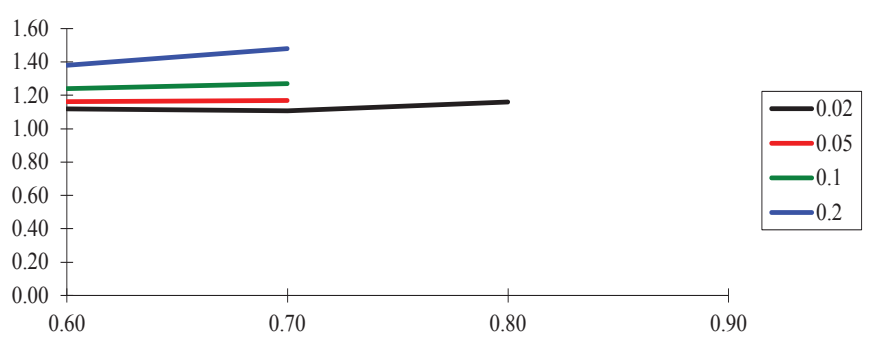

Figure 2. Dependence of the enterprise total costs on the level of the product reliability.

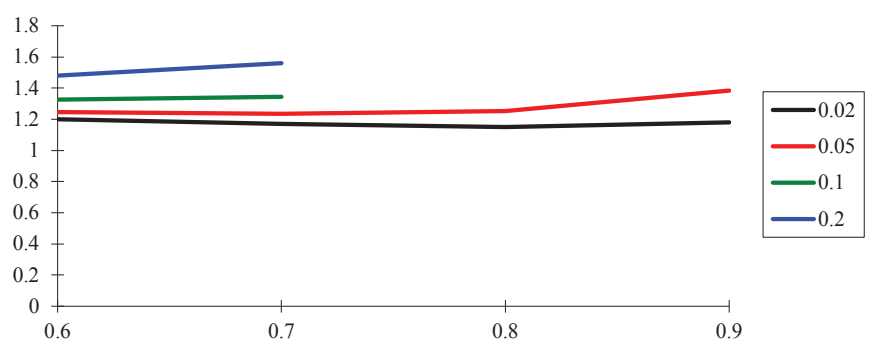

Figure 3. Dependence of the enterprise total costs on the level of the product reliability.

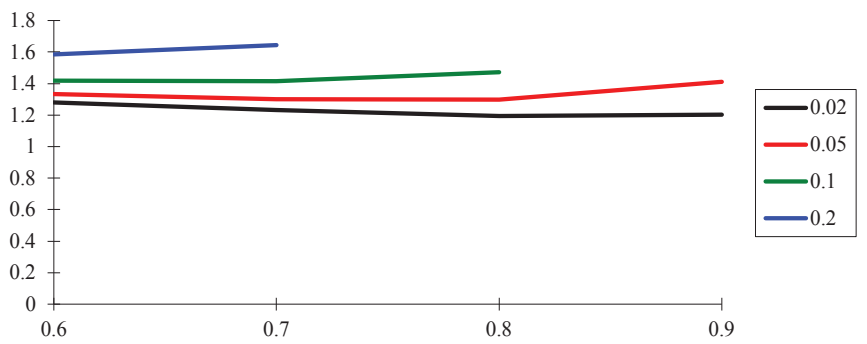

Figure 4. Dependence of the enterprise total costs on the level of the product reliability.

share on cost of the repaired product items per month on the relative value of total costs $C_{\Sigma}^{\prime \prime} / C$.

To achieve this purpose, there analysed the following component of the expression (19): $\frac{(1-p) A}{12 t_{g}\left[1+K^{1}\left(\frac{a}{k}\right)\right]}$

which does not practically affect the total aggregate costs $C_{\Sigma}^{\prime \prime} / C$. For example, at the formation of the data of Table 2 this value is changing within the limits of 0.0015 and 0,008 which is $1-2$ orders lower than other components in the expression: $\frac{C_{\Sigma}^{\prime \prime}}{C}=\left[1+K^{1}\left(\frac{a}{k}\right)\right]\left[1+\frac{(1-p) A}{12 n t_{g} C_{1}\left[1+K^{1}\left(\frac{a}{k}\right)\right]}\right]+K_{0}\left(1-p_{1}\right)$.

Moreover, according to the data of Table 1, the quick growth of value $K^{1}=\ln p / \ln p_{1}$ takes place simultaneously with the growth of the probability of non-failure operation; it results in substantial decrease of the value of considered component will lead to the growth of the value, that, in its turn, will cause the noticeable reduction of the

$$
\frac{C_{\sum}^{\prime \prime}}{C}\left[1+K^{1}\left(\frac{a}{k}\right)\right]\left[1+K_{0}\left(1-p_{1}\right)\right]
$$

considered addendum value. As a result, the expression can be presented in the following way:

That is, the total aggregate costs in the process of repair of the failed items depend on the product reliability, on the share of the cost of product spare parts and on the cost of increase of product non-failure operation.

As the last expression follows, the value $C_{\Sigma}^{\prime \prime} / C$ does not practically depend on the duration of the warranty service period and on the share of the repairing worker's wage in relation to the cost of the product items repaired by this worker per month, i.e. on the value $\mathrm{A}$.

Thus, when determining the total aggregate costs of manufacturing and warranty repair of the failed product items, these conditions allow replacing the complicated

formula: $\frac{C_{\sum}^{\prime \prime}}{C} \cong\left[1+K^{1}\left(\frac{a}{k}\right)\right]\left[1+\frac{(1-p) A}{12 t_{g}\left[1+K^{1}\left(\frac{a}{k}\right)\right]}+K_{0}\left(1-p_{1}\right)\right]$ 
by more simple ratio $\frac{C_{\sum}^{\prime \prime}}{C} \cong\left[1+K^{1}\left(\frac{a}{k}\right)\right]\left[1+K_{0}\left(1-p_{1}\right)\right]$

The results of calculations according to those expressions practically coincide.

The product characteristic is assumed to be normally distributed with unknown mean and known standard deviation. The optimal manufacturer's process quality level, production run length, warranty period, and retailer's order quantity can then be simultaneously determined by maximizing the expected total profit of society including both the manufacturer and the retailer (Chen et al. 2015).

Taking into consideration the above-mentioned material it is possible to draw the conclusion that the enterprise can achieve the minimal costs of manufacturing and warranty serving, but at the same time the level of the reliability of manufactures product does not meet the necessary requirements; it is in the area of the inadmissibly low values. Unsatisfactory quality of the warranty service can cause not only the loss of competitiveness, but also influence the transportation safety if it is a transportation company.

As a result, it is possible to consider that the quality of the warranty service, i.e. the probability of the non-failure operation is one of the most significant factors determining the enterprise costs under the conditions of the market economy.

\section{Conclusions}

It becomes more obvious that the main feature of modern innovative production should be the focus on the longterm prospects, basic researches implementation, diversification of operations, meeting the needs of consumers. One of the most important factors in achieving a high level of competitiveness is to provide manufacturer warranty to the issued products. After analyzing this topic, you can draw the following conclusions:

Guarantee services for the issued products is a set of works performed by manufacturer with the aim of providing technical and economic satisfaction and legal protection of the client-buyer, as a result of purchased products use. Innovative products manufacturers must provide all services associated with their products exploitation, which is carried out by warranty service and repair, value and quality of which have the greatest meaning for consumers.

Improving quality and duration period of the guarantee services is one of the conditions for the actual satisfaction of customer's needs (Mustofa et al. 2015). Integral indicator of the quality of guarantee services of the issued articles should include a set of indicators describing the warranty period, the level of manufactured products reliability, after-sales services quality and others.

Hence, justified topicality of the researches aimed at identification of cost expenses incurred by the manufacturer during production and guarantee services to produce innovative products. The results suggest that manufactur- er may obtain the minimum costs on the production and guarantee service, but in this context the level of reliability of products would not meet the requirements, ie, It lies in unacceptably low values area. Consequently, this quality of warranty services may entail not only the loss of manufacturer's competitiveness on the market, but is also connected to the human life safety, if their innovative products are used as component elements of the vehicle. As a result, we can say that the depth of the warranty, ie probability of failure-free functioning is one of determining factors of manufacturer cost expenses in the market economy.

\section{References}

Akyildiz IF, Wang X (2005) A survey on wireless mesh networks. IEEE Communications Magazine 43(9): S23-S30. https://doi. org/10.1109/MCOM.2005.1509968

Ang KH, Chong G, Li Y (2005) PID control system analysis, design, and technology. Transactions on Control Systems Technology 13: 559-576. https://doi.org/10.1109/TCST.2005.847331

Angrisani L, Schiano Lo Moriello R, D’Apuzzo M (2006) New proposal for uncertainty evaluation in indirect measurements. IEEE Transactions on Instrumentation and Measurement 55: 1059-1064. https://doi.org/10.1109/TIM.2006.876540

Blischke WR, Murthy DNP (2000) Reliability: Modeling, Prediction, and Optimization. Wiley, New York, 848 pp. https://doi. org/10.1002/9781118150481

Bolotin V (1990) The resource of vehicles and constructions. Mechanical Engineering Publisher, Moscow.

Chattopadhyay GN, Rahman A (2008) Development of lifetime warranty policies and cost models for free replacement lifetime warranty (FRLTW) policy. Reliability Engineering and System Safety 93: 522-529. https://doi.org/10.1016/j.ress.2007.02.005

Chen C-H, Chou C-Y, Lee W-C (2015) Economic order quantity, process quality level, warranty period, and production run length settings. Arabian Journal for Science and Engineering 40(2): 627-632. https://doi.org/10.1007/s13369-014-1522-8

Chien YH, Sheu SH, Chen JA (2004) Determining optimal warranty periods from the seller's perspective and optimal out-of-warranty replacement age from the buyer's perspective. International Journal of Science Education 36: 631-637. https://doi. org/10.1142/9789812702685_0010

Deniaud IF, Marmier F, Gourc D, Bougaret S (2016) A risk management approach for collaborative NPD project. International Conference on Industrial Engineering, Management Science and Application (ICIMSA), 23-26 May (2016), 1-5. https://doi.org/10.1109/ICIMSA.2016.7503986

Druzhinin G (1989) Reliability of Automatic Production Systems. Higher School, Moscow.

Jeyakumar K, Paul Robert T (2010) Joint determination of price, warranty length and production quantity for new products under free renewal warranty policy. International Journal for Quality research 4(1): 51-58

Kapur K, Lamberson L (1980) Reliability and System Design. Mir, Moscow.

Kleyner A, Sandborn P, Boyle J (2004) Minimization of life cycle costs through optimization of the validation program - a test sample size 
and warranty cost approach. Proceedings of Annual Reliability and Maintainability Symposium, 26-19 January (2004) Los Angeles, California, 553-557. https://doi.org/10.1109/rams.2004.1285505

Kurvinen M, Töyrylä I, Prabhakar Murthy DN, Kammerer M (2016) Warranty Fraud Management: Reducing Fraud and Other Excess Costs in Warranty and Service Operations. John Wiley \& Sons.

Majid HA, Jamahir NI, Samah AA (2013) Using reliability information and neuro-fuzzy to predict warranty cost: a case study in fleet vehicle. International Journal of Soft Computing and Engineering 3(4 September): 184-188.

Murthi D (2008) Product Reliability and Warranty: An Overview and Future Research. Brisbane, Australia.

Murthy DNP, Blischke WR (2005) Warranty Management and Product Manufacture. Springer Verlag, London, 302 pp.

Murthy DNP, Djamaludin I (2002) Product warranty - s review. International Journal of Production Economics 79: 231-260. https://doi. org/10.1016/S0925-5273(02)00153-6

Murthy DNP, Jack N (2007) Warranty Servicing, in Encyclopaedia of Statistics in Quality and Reliability. Wiley, New York, 1800 pp.

Murthy DNP, Osteras T, Rausand M (2007) Product Reliability - Specifications and Performance. Springer Verlag, London, 284 pp.

Murthy DNP, Solem O, Roren T (2004) Product Warranty Logistics: Issues and challenges. European Journal of Operational
Research 156(1): 110-126. https://doi.org/10.1016/S03772217(02)00912-8

Murthy DNP, Xie M, Jlang R (2003) Weibull Models. Wiley, New York, 408 pp. https://doi.org/10.1002/047147326X

Mustofa, Husniah H, Iskandar BP (2015) Optimal Servicing Strategy Involving Imperfect Repair and Preventive Maintenance for Products Sold with One-Dimensional Warranties. International Journal of Applied Mathematics and Statistics 53(1): 114-125.

Rahman A, Chattopadhyay G (2015) Long Term Warranty and After Sales Service. SpringerBriefs in Applied Sciences and Technology.

Saleh JH, Marais K (2006) Highlights from the early (and pre-) history of reliability engineering, Reliability Engineering and System Safety 91: 249-256. https://doi.org/10.1016/j.ress.2005.01.003

Thomas Marlin U, Rao Sridevi S (1999) Warranty economic decision models: a summary and some suggested directions for future research, Operations Research 47(6): 807-820. https://doi. org/10.1287/opre.47.6.807

Ventsel Y (1969) Probability Theory. Nauka, Moscow.

Wang X, Su C (2016) A two-dimensional preventive maintenance strategy for items sold with warranty. International Journal of Production Research 54(19): 5901-5915. https://doi.org/10.1080/00207543.20 16.1187314 